\title{
UNCERTAINTY, FEAR OF DENGUE AND PRACTICE OF PREVENTIVE MEASURES: A COMMUNITY-BASED SURVEY IN LAHORE, PAKISTAN
}

\author{
Afifa Anjum ${ }^{\natural}$, Fatima Kamran', Rafia Rafique'
}

\begin{abstract}
OBJECTIVE: To assess and correlate fear, uncertainty and practice of precautionary measures in relation to dengue fever (DF) in community from Lahore, Pakistan.

METHODS: This cross-sectional study was conducted in Lahore, Pakistan between September to November 2016. Multistage random sampling technique was used to enroll 400 adults from nine different towns. A self-constructed questionnaire was used to assess uncertainty, fear and practice of preventive measures. Data was analyzed using SPSS Version 21.
\end{abstract}

RESULTS: Out of 400 participants, 214 (53.5\%) were males and 186 (46.5\%) were females, with age ranging between $16-65$ years. In correlation analysis, fear had a slightly positive correlation with uncertainty $(r=0.02)$, and preventive practice $(r=0.01)$, whereas uncertainty had a negative correlation with preventive practice $(r=-0.22)$. In demographic components, age had the best correlation with fear $(r=0.12)$ as compared to others. Men reported to have greater uncertainty, $\mathrm{t}(\mathrm{I}, 198=2.1 \mathrm{I}, \mathrm{p}<0.04)$ and fear of having DF $[\mathrm{t}(\mathrm{I}, 198=3.7 \mathrm{I}$, $\mathrm{p}<0.00 \mathrm{I})]$, whereas women practised significantly more precautionary measures $[\mathrm{t}(\mathrm{I}, 198=-3.08, \mathrm{p}<0.00 \mathrm{I})]$. The participants whose relative had suffered from DF reported greater fear, $[\mathrm{t}(\mathrm{I}, 198=2.78, \mathrm{p}<0.0 \mathrm{I})]$ and uncertainty $[\mathrm{t}(\mathrm{I}, 198=2.04$, $p<0.05)]$. Hierarchical regression analysis revealed that uncertainty $(\beta=-0.34$; $p<0.00 I)$ and its interaction with gender $(\beta=0.22 ; p<0.01)$ were significant predictors of practice of preventive measures.

CONCLUSION: Being male, having fewer years of education and having relatives who had suffered from DF were correlated more with uncertainty and fear. Women practiced preventive measures for DF more than men practice and had a higher uncertainty as well.

KEYWORDS: Dengue (MeSH); Uncertainty (MeSH); Fear (MeSH); Prevention and Control (MeSH); Methods, Survey $(\mathrm{MeSH})$.

THIS ARTICLE MAY BE CITED AS: Anjum A, Kamran F, Rafique R. Uncertainty, fear of dengue and practice of preventive measures: a community-based survey in Lahore, Pakistan. Khyber Med Univ J 2020; I2(3):204-I0. DOI: 10.35845/kmuj.2020.187I3.

\section{INTRODUCTION}

$\mathrm{D}$ engue fever (DF) and its severe forms, dengue haemorrhagic fever (DHF) and dengue shock syndromes (DSS), have become major international public health concerns. According to Wold Health Organization, numbers of dengue cases have increased eight fold over the last two decades. 'Almost $50 \%$ of the global population is now at risk with an estimated 100-400 million infections each year. ${ }^{2}$ Of the total at risk population worldwide, South Asia accounts for approximately $70 \%$ cases. Not only is the number of cases increasing as the disease spreads to new areas, but explosive outbreaks are also occurring. ${ }^{1,2}$

Pakistan first reported case of dengue fever in 1994-95 in Karachi. ${ }^{3}$ Since then, dengue virus has spread in Pakistan, circulating throughout the year with a peak incidence in the post monsoon period. In 20 I I, Pakistan had the worst outbreak of dengue in which around
I. Institute of Applied Psychology, University of the Punjab, Lahore, Pakistan. Email区:anjumafifa@hotmail.com, anjumafifa@yahoo.com Contact \#: +92-300-4405065

Date Submitted: October 04,2018 Date Revised: September 07, 2020

Date Accepted: September 07, 2020

12,000 cases and 126 deaths were reported in less than a month time. Lahore was the epicentre with maximum number of cases followed by other cities of Punjab and Sindh. ${ }^{4}$ In the following years, multiple occurrences of dengue virus have occurred in different parts of the country. According to a recent report, dengue is still a major health concern with more than 19,000 cases in 2019. As there is no specific treatment available for DF, a major step that has been taken worldwide and in Pakistan to control the epidemic is prevention through health education. Making the information regarding dengue fever more available and use of popular sources of information like newspapers and television to disseminate information on a large scale regarding preventive strategies is always a useful strategy in controlling epidemics; the efficacy of which is important to be determined. A review of national and international research till date shows that efficacy of the prevention plans for DF control has been partially successful along with many demographic and knowledge related factors associated with (lack of) practice of precautionary measures by community samples, like gender, race, knowledge, self-efficacy, perceived threat, etc. ${ }^{6-9}$

A special issue in relation to $D F$ has been uncertainty associated with its diagnosis and effectiveness of treatment plans. ${ }^{14}$ Uncertainty is the inability to determine the meaning of illness-related events. It occurs when the decision maker is 
TABLE I: INTERCORRELATIONS AMONG DEMOGRAPHIC AND STUDY VARIABLES

\begin{tabular}{|c|c|c|c|c|c|c|c|c|}
\hline Variable & 2 & 3 & 4 & 5 & 6 & 7 & 8 & 9 \\
\hline I. Age & $0.18^{* * *}$ & -0.03 & -0.00 & 0.00 & -0.02 & 0.12 & -0.01 & 0.00 \\
\hline 2. Education (in years) & & $0.26 * *$ & $-0.20 * *$ & $-0.18 *$ & $-0.17 *$ & $-0.17 *$ & $-0.23 * *$ & 0.12 \\
\hline 3. Monthly Income & & & -0.01 & -0.05 & 0.00 & -0.00 & -0.02 & -0.05 \\
\hline 4. Uncertainty in diagnosis/ symptoms & & & & $0.38 * *$ & $0.35 * *$ & -0.07 & $0.73 * *$ & -0.10 \\
\hline 5. Uncertainty in treatment & & & & & $0.55 * *$ & 0.09 & $0.82 * *$ & $-0.20 * *$ \\
\hline 6. Uncertainty in precautionary measures & & & & & & 0.03 & $0.8 I^{* *}$ & -0.21 *** \\
\hline 7. Fear of Having DF & & & & & & & 0.02 & 0.01 \\
\hline 8. Uncertainty total & & & & & & & & $-0.22 * *$ \\
\hline 9. Practice of precautionary measures & & & & & & & & 0 \\
\hline
\end{tabular}

TABLE II: HIERARCHICAL MULTIPLE REGRESSION FOR PREDICTORS OF PREVENTIVE MEASURES OF DENGUE FEVER

\begin{tabular}{|c|c|c|}
\hline Variable & $\Delta R^{2}$ & $\beta$ \\
\hline Step I & $0.05^{* * *}$ & \\
\hline \multicolumn{3}{|l|}{ Control Variable } \\
\hline Gender & & $0.2 I^{* * *}$ \\
\hline Step 2 & $0.05^{* * *}$ & \\
\hline Gender & & 0.20 *⿻丷木 \\
\hline Uncertainty related to DF & & -0.20 *** \\
\hline Fear of suffering from DF & & 0.08 \\
\hline Step 3 & $0.04^{*}$ & \\
\hline Gender & & $0.22^{* * *}$ \\
\hline Uncertainty related to DF & & $-0.34 * * *$ \\
\hline Fear of suffering from DF & & 0.17 \\
\hline Fear X Gender & & -0.08 \\
\hline Uncertainty X Gender & & $0.22 * *$ \\
\hline Total $R^{2}$ & $0.14^{*} *$ & \\
\hline
\end{tabular}

${ }^{*} \mathrm{p}<.05,{ }^{* *} \mathrm{p}<.01,{ }^{* * *} \mathrm{p}<.001 . \mathrm{DF}=$ Dengue Fever

unable to evaluate objects or events with surety, or is unable to predict outcomes accurately. ${ }^{10,11}$ During the first major outbreak of disease in different cities of Pakistan in 2011, its most horrifying aspect was that people did not know exactly what were the specific symptoms that could differentiate between DF and any other common fever, how it could be treated, what could be the course of disease and prognosis and above all what could they do if they had it or as a preventive measure. This led to a wave of fear and panic in general public during outbreak. Since then, many prevention plans were employed by the government, information about symptoms and precautions was made public but still dengue is associated with a certain degree of uncertainty due to its nature. In fact, not knowing the diagnosis is a very serious stressor. ${ }^{12}$ Symptoms of an illness can lead to uncertainty when they change over time, are unpredictable and/or inconsistent such that they cannot be linked to a specific illness or disease or the outcome is unknown. ${ }^{13}$ Severity of DF ranges from mild fever to haemorrhagic fever and DSS, symptoms change over time, initial symptoms are not clearly distinguishable from other forms of fever, and thus are likely to be linked with high uncertainty in common people. The only most effective method to control or prevent the transmission of dengue virus is to combat vector mosquitoes through preventive measures. ${ }^{2}$ The Health Belief Model has been generally employed in dengue fever prevention and control. It proposes that a person's belief in the likelihood of contracting a disease and the disease being affecting health badly form the perceived threat to health. ${ }^{14}$ Next come a person's beliefs in adhering to health-related measures to prevent or reduce the disease and the costs (psychological or material) that limit a person to carry out the measures. To lessen the disease impact, there needs to be greater perceived benefits than costs convincing the person to carry out the proposed health-related measures. ${ }^{15}$ Findings of previous studies suggest that good knowledge about dengue fever does not always translate into adoption of preventive measures. ${ }^{16}$ For example recent community surveys in Combodia, Malaysia and Pakistan found poor practice related to dengue control and concluded that only education campaign is unlikely to have substantial effect on preventive practices, rather attitude and behavioural change models are required. ${ }^{7}$ Another study in Cuba found that economic status had indirect whereas risk perception had direct effect on dengue reduction practices. ${ }^{16}$ In a study in India, it was found that fear related to DF was widespread but practices were relatively low. ${ }^{17}$ These findings point to the possibility of intervening variables like uncertainty and fear that is inevitable to be present in case of DF since it is relatively new to Pakistani population, both doctors and patients. Accurate knowledge of the disease, prevention, treatment and other related variables is basis for predicting adherence to treatment as well as success of any prevention programme that is currently lacking in Pakistani. To make dengue control plans and media awareness campaigns successful with long term success, it is important to understand if common people believe that whatever is known about DF is sufficient and correct as well as might actually help them get rid of the disease. This study was conducted to find the level of uncertainty in relation to 


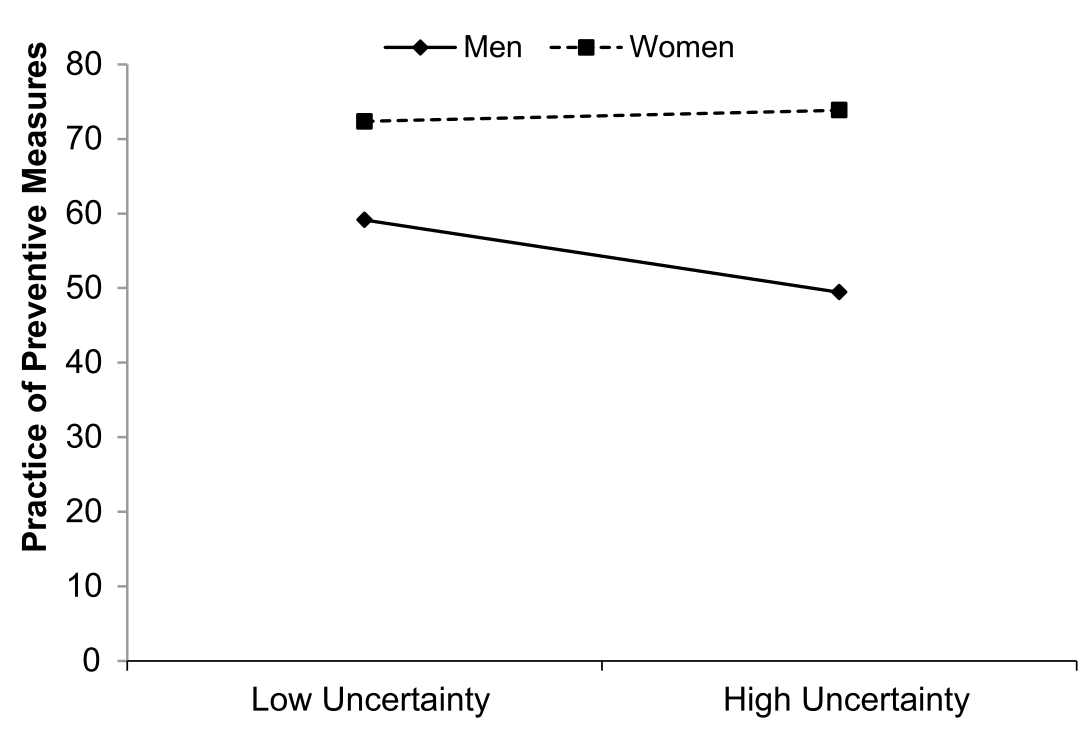

Figure I: Interaction of gender with uncertainty in predicting practice of preventive measures

DF and the role of uncertainty and fear of DF in practice of precautionary measures.

\section{METHODS}

This cross-sectional community survey was conducted in Lahore, Pakistan between September to November, 2016 which is considered as peak season of DF outbreak. Sample size was calculated using the formula ${ }^{18} \mathrm{n}=$ $\mathrm{N} / \mathrm{I}+\mathrm{N}(\mathrm{e})^{2}$ where $\mathrm{n}=$ required sample size, $\mathrm{N}=$ population size i.e 10.8 million (estimated population of Lahore in $\left.2016^{19}\right)$ and $\mathrm{e}=$ level of precision (0.05). A final sample of 400 was enrolled using the formula. Multistage sampling technique was used to select the sample in three stages. At stage one, four out of nine towns of Lahore was selected randomly. At stage two, area clusters were randomly selected from each town. Next, one member from each household was selected via door to door survey through purposive sampling. Inclusion criteria entailed: one member from each household, either heads of the family or any other family member who reported taking responsibility for domestic tasks regarding prevention of DF, being adult, i.e. age $\geq 18$ years, both genders, and residing in the household for at least last three months. Participants were approached at their homes or workplaces such as shops of the local market areas or offices in a cluster. A total of 480 questionnaires were delivered, out of which 400 were obtained qualifying for data analysis. The overall response rate of participants was $83 \%$. Ethical considerations were fulfilled. The study was approved by the Research Evaluation Committee, University of the Punjab, Lahore, Pakistan. The participants were informed about the nature of the research and their written consent to participate in the research was taken. Anonymity of the participants and confidentiality of the data was maintained.

The participants were asked demographic information regarding age, gender, education, marital status, monthly income and occurrence of DF in the first degree relatives. A selfconstructed questionnaire on uncertainty in relation to DF comprising of 3 questions assessing perceived degree of uncertainty about diagnosis/symptoms, treatment and preventive measures of DF was administered. The questionnaire was constructed by taking guidelines from Uncertainty in IIIness Scale Community sample ${ }^{20}$ and the medical practitioners from government hospitals of Lahore. Two aspects of uncertainty, i.e uncertainty about diagnosis and treatment were adopted from Mishel theory and the third aspect, uncertainty related to preventive Mishel's theory of uncertainty, ${ }^{10}$ Mishel measures, was added after consultation with the doctors dealing with DF patients. After construction of the items, the scale was presented to five community members and five patients suffering from DF and content was amended if and as required. Finally, expert clinician review was obtained by presenting the scale to three doctors dealing with DF, different from those consulted for construction. Example item include "Do you think that treatment available and being practiced by doctors for DF really works? "Each item was rated on four point scale, with $0=$ not at all, $I=$ to some extent, $2=$ to a great extent and $3=$ fully. It yielded separate scores for each of the categories of uncertainty as well as overall score. The alpha reliability for the overall scale was 0.71 . Intercorrelations between all three items and correlations of each item with total scale score were all above 0.70 , indicating construct validity of the scale. One question was asked to assess level of fear of having DF as experienced by the participants with 4 point rating scale, ranging from 0 to 3 . The item was: I am afraid that I might catch DF like other people around me. Finally, practice of preventive measures was assessed using the self developed questionnaire comprising of 19 items. It included questions such as the use of mosquito repellent, covering water tanks, proper removal/drying of rain water, wearing full sleeves, etc. All those precautionary measures were included in the questionnaire that has been frequently advertised by the government through electronic as well as print media. Each item was rated on six points rating scale, with $0=$ not related, $I=$ less than it, $2=$ once in a month, $3=$ once a week, $4=$ every second or third day and $5=$ daily. It yielded high alpha reliability of 0.82 . The scale was in Urdu to make the items understandable to the participants.

Analysis included descriptive analysis, bivariate correlations between study variables and demographic variables measured on interval/ratio scale i.e. age, education and monthly family income, and $\mathrm{t}$-test for dichotomous variables i.e. gender and DF in relatives to find differences in study variables. Hierarchical regression analysis was run 
to find if uncertainty and fear predicted practice of preventive measures and if any demographic variable moderated the association while controlling for demographic variables found significantly related to DF in correlation/t-test analysis.

\section{RESULTS}

A total of 400 participants took part in the survey. The sample included 214 men and 186 women with age ranging between 16-65 years, education between 5 to 18 years. Majority 280 (70\%) were married participants. Participants belonged to all income groups ranging from low to high income as (in thousands) $\leq 20(n=92), 20-50$ $(n=106), 5 I-100 \quad(n=93)$, and $\geq 100$ $(n=109)$. About half $(46.5 \%)$ of the participants reported that at least one of their first degree relatives had suffered from DF in recent outbreaks. On all three scales of uncertainty, scores were close to midpoint of the scale indicating presence of uncertainty about Dengue Fever (DF). Fear of having dengue was below midpoint. On practice of preventive measures, with score range of 0 to 95 , minimum score obtained by any participant were 19, with mean 48 (rounded) indicating practices of preventive measures to some extent.

Correlation analysis showed a negative relationship between uncertainty and practice of preventive measures. The participants who experienced greater uncertainty reported less practice of preventive measures of DF. Fear had no relation with uncertainty or practice of preventive measures. Among demographics, education was negatively associated with fear and uncertainty. Participants who were less educated reported high fear of DF and high uncertainty. Age and monthly income had no relation with all three study variables, i.e fear, uncertainty and practice of preventive measures.

Independent sample t- test on gender differences revealed that men had greater uncertainty, $t(1,198)=2.11, p$ $=.03$, Cohen's $d=.3$, and fear of having $\mathrm{DF}, t(\mathrm{I}, 198)=3.7 \mathrm{I}, p<.00 \mathrm{I}$, Cohen's $d=.53$, whereas women were more in practice of precautionary measures, $t$ $(I, 198)=-3.08, p<.001$, Cohen's $d=$ -
.44. Second set of $t$ test analyses was between groups whose any close (first degree) relative had suffered from DF or not. The participants whose relative had suffered from DF were suffering from more fear, $t(1,198)=-2.78, p=$ .01 , Cohen's $d=-.40$, and had greater uncertainty related to diagnosis and symptoms, $t(1,198)=2.04, p=.04$, Cohen's $d=.29$.

Hierarchical regression analysis was conducted in three steps to find predictors of preventive measures of DF. In first step, gender was entered as control variable as it was the only demographic variable that was significantly related to practice of preventive measures. In step two, both independent variables (IVs), uncertainty and fear and in step 3, interactions of both IVs with gender were entered. Results are summarized in Table II. The overall model was significant explaining $14 \%$ variance in the practice of preventive measures. Each step resulted in significant increase in explained variance of the model. Fear of suffering from DF did not predict practice of preventive measures whereas both uncertainty and its interaction with gender were significant predictor of practice of preventive measures. Higher uncertainty lead to less practice of preventive measures. Overall, in women, when uncertainty increased, practice of precautionary measures also increased. On the other hand, the relationship was inverse for men. When uncertainty was high in men, practice of preventive measures decreased (Figure I).

\section{DISCUSSION}

The present study found significant role of uncertainty in practice of preventive measures with differences across genders as well as relation between participant characteristics and study variables. Initial findings on participant characteristics showed that education was negatively related with fear and all aspects of uncertainty. Those with fewer years of education had greater fear of having DF and greater uncertainty. Syed M, et al. found positive association of education with knowledge of DF, which indicates that greater education leads to greater knowledge of DF and consequently lesser uncertainty as both uncertainty and fear might rise in case of less or ambiguous information and knowledge. ${ }^{21}$ However, education had no relationship with practice of preventive measures. A study found that although attitudes were favourable regarding dengue control but preventative practices were inadequate. ${ }^{20}$ Gunathilaka N, et al. also found that although educational attainment was positively associated with knowledge of dengue, there was no correlation between knowledge about dengue and preventive practices. ${ }^{22}$

Further, there were significant differences in fear and uncertainty between groups with and without DF in relatives. This indicated that dengue history in close family was an important factor which induced fear among respondents of the study. The people whose relative had suffered from DF were experiencing more fear, and had greater uncertainty related to diagnosis and symptoms. Past studies have documented evidence of anxiety and fear in patients suffering from $D^{23,24}$ but this study further indicates that the fear extends to the first degree relatives of DF patients as well. As the first degree relatives are generally living in the same household or locality (and might be caregivers as well), they develop the fear that they also might catch the virus from the same environment. These findings are in line with study on fear on dengue in community samples. ${ }^{17}$ Men, in current study, reported greater fear of having DF and uncertainty. Dengue statistics in Pakistan show a greater incidence as well as death rate by DF in men (but there is no specific reason why it happened so except that men might be more exposed to mosquito and virus due to greater mobility outside home). This might be the direct influencing factor of fear of having DF in men as well as greater uncertainty about all aspects including diagnosis, symptoms, treatment and prevention. ${ }^{2}$ Women practiced more preventive measures than men for dengue fever. Regression analysis also indicated gender as a significant predictor of 
practice of preventive measures. This might be because it is generally believed in Pakistan that females should take care of the households while the males have other responsibilities outside home. These findings are also consistent with a study carried out by Ahmed N, et al among males, who found that Females had higher practice behaviour than males in prevention of $\mathrm{DF}^{24}$ Further, the findings established the moderating role of gender in the relationship between uncertainty and practice of preventive measures. In women, greater uncertainty led to greater practice whereas in men, greater uncertainty led to less practice of preventive measures. Whether women were certain or not about the illness, they took preventive measures more than men and their practice further increased with increase in uncertainty. It is generally well known that women naturally are more concerned about self and home than men, so when they are uncertain about the specificities of illness, they may not take risk of being careless. In such cases, they may become more vigilant in order to avoid any mishap. In case of men, the use of preventive measure decreases with uncertainty. Gender role socialization theories might explain such differences. In Pakistan, socialization process is such that females are mostly expected to conform, whether they agree or not with the issue. Female gender roles are submissive, caring and taking things sensitively, at least in majority of common people. Thus when unsure, women even more follow to make sure that they do not doubt or are not careless. On the other hand, results regarding men are consistent with previous researches that indicate that uncertainty of illness brings negative attitudes, behaviours and practices in people. ${ }^{16,19,25}$ It reduces an individual's self efficacy, diminishes his/her mastery over the external events and weakens his/her sense of resourcefulness and skilfulness. ${ }^{26}$ Tackett AP, et al. ${ }^{27}$ mentioned similar findings in their work that uncertainty of illness is responsible for trauma, negative health outcomes, and poor quality of life in patients. From these findings, it can be deduced that people who are uncertain about aspects of the illness, fail to practice control in their lives, so it is unlikely for them to use precautionary measures for disease control. It might be that the information provided by different government institutions in Pakistan has been insufficient to address people's understanding of disease diagnosis, treatment and prevention in general and the educational methods used have been less effective specifically for men. Whatever the reason might be, uncertainty and resulting lack of preventive measures in men warrants attention.

Regression analysis also indicated that fear of dengue fever didn't predict use of preventive measures. Thus, the findings suggest that if participants had fear that they could catch DF, it did not translate into practice. Although fear of illness might lead towards preventive measure and precautionary actions, but a recent research in India also showed lack or relationship between fear and preventive practice ${ }^{19}$ and further strengthened that there are other factors that might inter play like uncertainty, health beliefs and health attitudes. ${ }^{28}$ Further exploration by researchers using careful methodology is needed. Qualitative techniques might help in such explorations.

\section{LIMITATIONS OF THE STUDY}

Due to the cross-sectional nature of the survey research design, cause and effect relationship between uncertainty of illness and use of precautionary measures cannot be determined. Longitudinal researches with better control are needed to be carried out to have the better understanding of this relationship. Moreover, the present research was carried out with the general public; future researches with dengue victims can be informative with respect to uncertainty of illness and effective practice of preventive measures. A comparative approach with general public and dengue victims can also help in understanding level of uncertainty and use of precautionary measures as practiced by both groups.

\section{CONCLUSION}

This study concluded that uncertainty related to dengue fever is present to some extent in the participants. Being male, having fewer years of education and having relatives who had suffered from DF were associated with greater uncertainty and fear. Uncertainty predicted practice of preventive measures whereas fear was nonsignificant. Women practiced preventive measures more than men did when uncertainty was high and men practiced more when uncertainty was low. Overall, women practiced more preventive measures than men. The study findings point towards the need of public awareness programmes, specifically targeting male and less educated members of the society as they are less inclined towards preventive practices. Such programmes should specially address and try to deal with the issue of uncertainty by providing statistics on efficacy and effectiveness of different measures, modify their belief systems regarding the necessity of preventive measures and advocate gender equal role in the disease management.

\section{REFERENCES}

I. World Health Organization (WHO). Dengue and severe dengue WHO fact sheet;2020. [Accessed on: August 21, 2020]. Available from URL: https://www.who.int/newsroom/fact-sheets/detail/dengueand-severe-dengue.

2. World Health Organization, Regional Office for South-East Asia. Comprehensive Guideline for Prevention and Control of Dengue and Dengue Haemorrhagic Fever. Revised and expanded edition.; 20I I. [Accessed on: September 12, 2018]. Available from URL: https://apps.who.int/iris/bitstream/ handle/ I0665/204894/B475 I.pdf?s equence $=\mid$ \& \&isAllowed $=y$.

3. Ahmad S, Aziz MA, Aftab A, Ullah Z, Ahmad MI, Mustan A. Epidemiology of dengue in Pakistan, present prevalence and guidelines for future control. Int J Mosq Res 2017;4(6): 25-32.

4. Fatima Z. Dengue infection in Pakistan: not an isolated problem. Lancet Infect Dis 2019;19(12): I287-8. DOI: I0.10I6/SI4733099(I9)3062I-8. 
5. Sulistyawati S, Surahma SAM, Sukesi TW. Understanding Community Involvement on Dengue Prevention in Sleman, Indonesia: A Free Listing Approach. J UOEH 2020;42(3): 23I-6. DOI: 10.7888/juoeh.42.23I.

6. Rakhmani AN, Limpanont $Y$, Kaewkungwal J, Okanurak K. Factors associated with dengue prevention behaviour in Lowokwaru, Malang, Indonesia: a cross-sectional study. BMC Public Health 2018;18(I):619. DOI: 10 . | |86/s | 2889-0|8-5553-z.

7. Murphy A, Rajahram G, Jilip J, Maluda M, William T, Hu W, et al. Incidence and epidemiological features of dengue in Sabah, Malaysia. PLoS Negl Trop Dis 2020;।4(5):e0007504. DOI: 10. |37|/journal.pntd.0007504

8. Msellemu D, Gavana T, Ngonyani H, Mlacha YP, Chaki P, Moore SJ. Knowledge, attitudes and bite prevention practices and estimation of productivity of vector breeding sites using a Habitat Suitability Score (HSS) among households with confirmed dengue in the 2014 outbreak in Dar es Salaam, Tanzania. PLoS Negl Trop Dis $2020 ; 14(7)$ e 0007278 . DOI:10.137//journal.pntd.000727 8.

9. Yousaf MZ, Siddique A, Ashfaq UA, Ali M. Scenario of dengue infection \& its control in Pakistan: An update and way forward. Asian Pac J Trop Med 2018; II(I): I5-23. DOI: 10.4103/1995-7645.223529.

10. Sabir M, Ali Y, Muhammad N. Forecasting incidence of dengue and selecting best method for prevention. J Pak Med Assoc 2018;68(9): 1383-6.

II. Hung TM, Wills B, Clapham HE, Yacoub S, Turner HC. The uncertainty surrounding the burden of post-acute consequences of dengue infection. Trends Parasitol 2019;35(9):673-6. DOI:10.1016/ j.pt.2019.06.004.

12. Khare RK, Powell ES, Venkatesh AK, Courtney DM. Diagnostic uncertainty and costs associated with current emergency department evaluation of low risk chest pain. Crit Pathw Cardiol 2008;7(3):19|-6. DOI: 10.1097/ HPC.0b0I3e3I8I76faal.

13. Zahir A, Ullah A, Shah M, Mussawar A. Community participation, dengue fever prevention and control practices in Swat, Pakistan. Int J MCH AIDS 2016;5(I):39-45. DOI: $10.21106 /$ ijma.68.

14. Siddiqui TR, Ghazal S, Bibi S, Ahmed W, Sajjad SF. Use of the health belief model for the assessment of public knowledge and household preventive practices in Karachi, Pakistan, a Dengue-Endemic City. PLoS Negl Trop Dis $20 \mid 6$; I0 ( I I ):e $0005 \mid 29$. DOI: 10.137 I/journal.pntd.0005 I 2 9x.

15. Wong LP, AbuBakar S. Health beliefs and practices related to dengue fever: a focus group study. PLoS Negl Trop Dis 2013;7(7): e23।0. DOI: 10.137I/journal.pntd. 0002310.

16. Kumaran E, Doum D, Keo V, Sokha L, Sam BL, Chan V, et al. Dengue knowledge, attitudes and practices and their impact on communitybased vector control in rural Cambodia. PLoS Negl Trop Dis 20|8; I 2(2):e0006268. DOI: 10.1371/journal.pntd.0006268.

17. Daudé É, Mazumdar S, Solanki V. Widespread fear of dengue transmission but poor practices of dengue prevention: $A$ study in the slums of Delhi, India. PLoS One 20।7;। 2(2):e0I7|543. DOI: 10.1371/journal.pone.0171543.

18. Pourhoseingholi MA, Vahedi $M$, Rahimzadeh M. Sample size calculation in medical studies. Gastroenterol Hepatol Bed Bench 2013 Winter;6(I):14-7.

19. Beauro of Statistics, Government of Punjab, Lahore. Punjab Development Statistics 2016. [Accessed on: September 12, $2018]$. Available from URL: http://bos.gop.pk/system/files/Dev2016.pdf.

20. Mishel $\mathrm{MH}$ : Uncertainty in Illness Scale Manual. Chapel Hill, NC:
University of North Carolina School of Nursing; 1997.

2I. Syed M, Saleem T, Syeda UR, Habib M, Zahid R, Bashir A, et al. Knowledge, attitudes and practices regarding dengue fever among adults of high and low socioeconomic groups. J Pak Med Assoc 2010; 60(3):243-7.

22. Gunathilaka N, Chandradasa M, Champika L, Siriwardana S, Wijesooriya L. Delayed anxiety and depressive morbidity among dengue patients in a multi-ethnic urban setting: first report from Sri Lanka. Int J Ment Health Syst 20I8; I2:20. DOI: $10.1 \mid$ |86/s/3033018-0202-6

23. Hashmi AM, Butt Z, Idrees Z, Niazi M, Yousaf Z, Haider SF, et al. Anxiety and depression in patients with DF and their correlation with symptom severity. Int J Psychiat Med 2012;44(3): I99-2I0. DOI: 10. 2190/PM.44.3.b.

24. Ahmed N, Taneepanichskul S. Knowledge, attitude and practice of dengue fever prevention among the people in Male, Maldives. J Health Res 2007;22(Suppl. 2008):33-7.

25. Khan E, Kisat M, Khan N, Nasir A, Ayub S, Hasan R. Demographic and clinical features of dengue fever in Pakistan from 2003-2007: a retrospective cross-sectional study. PloS One 2010;5(9):el2505. DOI: 10.1371/journal.pone.00I 2505.

26. Raza FA, UrRehman S, Khalid R, Ahmad J, Ashraf S, lqbal M, Hasnain $S$. Demographic and clinicoepidemiological features of dengue fever in Faisalabad, Pakistan. PloS One 20I4; 9(3):e89868. DOI: I0.1371/journal.pone.01 I2196.

27. Tackett AP, Cushing CC, Suorsa KI, Mullins AJ, Gamwell KL, Mayes s, et al. Illness uncertainty, global Psychological distress, and posttraumatic stress in pediatric Cancer: A preliminary examination using a path analysis approach. J Pediatr Psychol 2016;4I(3):309-I8. DOI: 10.1093/jpepsy/jsv093.

28. Selvarajoo S, Liew K, Tan W, Lim XY, Refai WF, Zaki RA, et al. Knowledge, attitude and practice on dengue 
prevention and dengue seroprevalence in a dengue hotspot in Malaysia: A cross-sectional study. Sci Rep 2020; I0(I):9534.
DOI:10.1038/s4I598-020-662/2-5

\section{AUTHORS' CONTRIBUTIONS}

Following authors have made substantial contributions to the manuscript as under:

AA: Conception and study design, acquisition, analysis and interpretation of data, drafting the manuscript, approval of the final version to be published

FK: Analysis and interpretation of data, drafting the manuscript, critical review, approval of the final version to be published

RR: Study design, critical review, approval of the final version to be published

Authors agree to be accountable for all aspects of the work in ensuring that questions related to the accuracy or integrity of any part of the work are appropriately investigated and resolved.

\section{CONFLICT OF INTEREST}

Authors declared no conflict of interest GRANT SUPPORT AND FINANCIAL DISCLOSURE NIL

\section{DATA SHARING STATEMENT}

The data that support the findings of this study are available from the corresponding author upon reasonable request

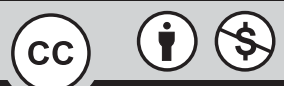

BY NC
This is an Open Access article distributed under the terms of the Creative Commons Attribution-Non Commercial 2.0 Generic License.

KMUJ web address: www.kmuj.kmu.edu.pk

Email address: kmuj@kmu.edu.pk 